\title{
ERRATUM
}

\section{Erratum to: Nature apps: Waiting for the revolution}

\author{
Paul Jepson, Richard J. Ladle
}

Published online: 14 December 2015

Erratum to: Ambio (2015) 44:827-832

\section{DOI 10.1007/s13280-015-0712-2}

Unfortunately, in the original publication of the article, Footnote 1 appeared incorrectly. The correct version of Footnote 1 is provided in this erratum.

Footnote 1: Dataset doi:10.5287/bodleian:st74cq573.
Paul Jepson $(\bowtie)$

Address: School of Geography and the Environment, Oxford University, Oxford, UK.

e-mail: paul.jepson@ouce.ox.ac.uk

Richard J. Ladle

Address: Institute of Biological and Health Sciences, Federal University of Alagoas, Maceió, AL, Brazil. 